\title{
Protein Phosphatase 1 Beta is Modulated by Chronic Hypoxia and Involved in the Angiogenic Endothelial Cell Migration
}

\author{
Dominga Iacobazzi ${ }^{a}$ Indira Garaeva ${ }^{a}$ Ambra Albertario Myriam Cherifa $^{a}$ \\ Gianni D. Angelini ${ }^{a}$ Massimo Caputo ${ }^{a, b}$ Mohamed T. Ghorbel ${ }^{a}$ \\ ${ }^{a}$ Bristol Heart Institute, University of Bristol, Bristol, UK, ${ }^{b}$ Rush University Medical Center, Chicago, IL, USA
}

\section{Key Words}

Protein phosphatase 1 • Endothelial cell migration • Angiogenesis • Hypoxia

\begin{abstract}
Background/Aim: Endothelial cell migration is required for physiological angiogenesis, but also contributes to various pathological conditions, including tumour vascularization. The mRNA expression of PP1c $\beta$, the beta isoform of the catalytic PP1 subunit, was shown to be upregulated in chronic hypoxia. Since hypoxia is a major regulator of angiogenesis, the potential role of PP1c $\beta$ in angiogenesis was investigated. Methods: We examined PP1c $\beta$ protein level in pediatric heart following chronic hypoxia and found PP1c $\beta$ upregulation in cyanotic compared with acyanotic myocardium. By treating HUVEC cells with hypoxia mimicking agent, PP1c $\beta$ protein level increased with maximum at 8 hours. The effect of PP1c $\beta$ pharmacological inhibition, knockdown and overexpression, on endothelial cell migration and morphogenesis, was examined using in vitro wound healing scratch assay and endothelial tube formation assay. The PP1c $\beta$ knockdown effects on F-actin reorganization (phalloidin staining), focal adhesion formation (vinculin) and focal adhesion kinases (FAK) activation, were evaluated by immunocytochemical staining and immunoblotting with specific antibodies. Results: PP1c $\beta$ knockdown significantly reduces endothelial cell migration, but does not have any significant effect on endothelial tube formation. Endothelial cell migration in the knockdown group is restored to the control level upon consecutive transfection with PP1c $\beta$ cDNA. PP1c $\beta$ overexpression does not significantly affect endothelial cell migration. Furthermore, PP1c $\beta$ knockdown induces profound cytoskeletal reorganization, loss of focal adhesion sites and impairment of focal adhesion kinases (FAK) activation. Conclusions: PP1c $\beta$ is regulator of endothelial cell migration, which is critical in the angiogenic process. PP1c $\beta$ inhibition reduces endothelial cell migration through focal adhesion turnover and actin polymerization pathways.
\end{abstract}




\begin{tabular}{|c|c|c|}
\hline Cellular Physiology & Cell Physiol Biochem 2015;36:384-394 & \\
\hline and Biochemistry & $\begin{array}{l}\text { DOI: 10.1159/000430257 } \\
\text { Published online: May 07, } 2015\end{array}$ & $\begin{array}{l}\text { O } 2015 \text { S. Karger AG, Basel } \\
\text { www.karger.com/cpb }\end{array}$ \\
\hline
\end{tabular}

\section{Introduction}

Angiogenesis is a complex multistep process that involves endothelial cell (EC) proliferation, degradation of the basement membrane and extracellular matrix (ECM), EC migration and tube formation [1,2]. These steps are required in the physiological angiogenic process, but also contribute to various pathological conditions, including tumor vascularization.

Protein phosphatase 1 (PP1) belongs to a major family of serine/threonine specific phosphatases and is universally expressed in all eukaryotic cells. The roles of PP1 have been well established in diverse cellular processes, including cell division, glycogen metabolism, mRNA splicing and apoptosis [3]. Furthermore, PP1 plays a role in multiple signaling pathways that are involved in angiogenic processes and its activity is likely mediated by VEGF-A-induced gene expression of phosphatase actin regulating protein-1 (Phactr-1) [4].

Each functional PP1 enzyme consists of a catalytic (PP1c) and regulatory/targeting (R) subunit. Three mammalian PP1c genes have been identified, encoding PP $1 \alpha$, PP $1 \beta / \delta$ and PP $1 \gamma_{1}$ and PP $1 \gamma_{2}$, the latter two being splice variants of the PP1 $\gamma$ gene [5]. The roles of each isoform are yet to be determined. The low number of PP1c isoforms, and their high amino acid sequence identity, supports the notion that it is the R subunits that modulate substrate specificity of PP1c and target the catalytic subunits to particular subcellular localizations $[5,6,7]$. Therefore, the interactions between catalytic and regulatory subunits produce a variety of differentially localized holoenzymes and are fundamental for PP1 to achieve its required functional specificity.

PP1c $\beta$ is a specific isoform of the catalytic subunit of PP1 enzyme and its gene is localized to chromosome $2 \mathrm{p} 23$ in humans [8].

If the physiological PP1c $\beta$ activity contributes to the normal maintenance of some cellular functions such as endothelial cell barrier protection, cytoskeleton structure support $[9,10,11]$ and DNA repair [12], its overexpression has been observed in certain cancers, like metastatic melanoma [13], malignant pancreatic tumors [14, 15], and breast cancers [16, 17]. Additionally, we have recently shown that hypoxia, a major regulator of angiogenesis [18], upregulates the mRNA of protein phosphatase type 1 beta (PP1c $\beta$ ) in cyanotic children with tetralogy of Fallot (TOF) [19]. Furthermore, mRNA expression of HIF-1 $\alpha$, and the expression of its target genes VEGF and EPO (erythropoietin) is markedly increased in newborns with persistent pulmonary hypertension of the newborn (PPHN), and cyanotic congenital heart disease (CCHD), [20]. Since children with CCHD commonly present with widespread formation of collateral blood vessels [21], and VEGF is a potent stimulator of angiogenesis that is upregulated in hypoxia, PP1c $\beta$ mRNA upregulation in CCHD implies its potential role in vascular growth.

The finding that PP1c $\beta$ is also overexpressed in several cancers, and that angiogenesis is a hallmark of cancer development, with certain tumours developing a hypoxic microenvironment to further potentiate its vascularization and growth [22], suggest that PP1c $\beta$ might play an essential role in angiogenesis.

Hence, we investigated the role of PP1c $\beta$ in angiogenesis. We first showed that PP1c $\beta$ protein is upregulated in cyanotic compared with acyanotic myocardium. Then we showed that treating HUVEC cells with $\mathrm{CoCl}_{2}$, a hypoxia mimicking agent, increases PP1c $\beta$ protein level in a time-dependent manner. By using different PP1 pharmacological inhibitors and through the knockdown of PP1c $\beta$ by siRNA transfection we found that PP1c $\beta$ downregulation significantly reduced endothelial cell migration in vitro, which was restored by the consecutive transfection with PP1c $\beta$ cDNA. No significant difference in endothelial tube formation between PP1c $\beta$ siRNA transfected HUVEC and the control group was observed, implying that $\mathrm{PP} 1 \mathrm{c} \beta$ is involved in the migration process of angiogenesis rather than in the subsequent step of tube formation. We also demonstrated that PP1c $\beta$ role in endothelial cell migration involves cytoskeleton reorganization through focal adhesions and focal adhesion kinase (FAK) signaling.

\section{KARGER}




\section{Cellular Physiology Cell Physiol Biochem 2015;36:384-394 \begin{tabular}{l|l} 
and Biochemistry Published online: May 07, 2015 & $\begin{array}{l}\text { C) 2015 S. Karger AG, Basel } \\
\text { www.karger.com/cpb }\end{array}$ \\
\hline
\end{tabular} \\ Iacobazzi et al.: PP1 b Role in Angiogenesis}

\section{Materials and Methods}

The collection of human right ventricle specimens used in this study, was approved by the North Somerset and South Bristol Research Ethics Committee (REC reference 07/H0106/172), The National Research Ethics Service, England. Parental informed written consent was gained for all patients. Twelve patients with a diagnosis of cyanotic $(n=6)$ or acyanotic $(n=6)$ Tetralogy of Fallot undergoing surgical repair at the Bristol Royal Hospital for Children were studied.

Immunohistochemistry

Right ventricular specimens were fixed in 4\% paraformaldehyde, washed in PBS, and embedded in paraffin, and 4- $\mu \mathrm{m}$ sections were obtained. Immunohistochemistry was performed with the ABC-Kit from DakoCytomation (Glostrup, Denmark). Photos were taken at $20 \times$ magnification.

\section{Cell culture}

HUVECs were purchased from Lonza and were cultured at $37^{\circ} \mathrm{C}$ in humidified $5 \% \mathrm{CO}_{2}$ in endothelial growth medium containing 2\% FBS (Lonza, CC-4176). HUVECs between passage eight and twelve were used in the experiments. To mimic hypoxic conditions, $\mathrm{CoCl}_{2}[23]$ was added to the culture medium $(100 \mu \mathrm{M})$ for the indicated times.

In vitro DNA and siRNA transfection and co-transfection

After seeding in a 24-well plate, HUVECs ( 35000/well) were allowed to settle for $24 \mathrm{~h}\left(37^{\circ} \mathrm{C}, 5 \% \mathrm{CO}_{2}\right)$. For PP1c $\beta$ overexpression, HUVECs were transfected with PP1c $\beta$ full-length cDNA encoding plasmid $(1 \mu \mathrm{g} /$ well), pCMV-SPORT6.ccdb vector (Thermo Scientific). The pmaxGFP plasmid (Green Fluorescent Protein, Amaxa) was used as a control. Transfection was performed using JetPEI ${ }^{\mathrm{TM}}$-HUVEC (PolyPlus Transfection) according to the manufacturer's instructions.

For PP1c $\beta$ knockdown, HUVECs were transfected with PP1c $\beta$ siRNA (10 nM, Qiagen) and with scrambled siRNA (10 nM, Qiagen) using commercialy available transfection agent INTERFERin (PolyPlus Transfection).

DNA/siRNA co-transfection was performed by siRNA transfection followed by DNA transfection 4 hours later. Twenty-four hours later, cells were subjected to migration and network formation assays, as below.

\section{Viability assay}

Viability and apoptosis of cultured cells in presence or absence of the PP1 inhibitor Calyculin (1nM, Sigma) was detected using the Calcein AM Cell Viability Assay Kit (Biotium) following manufacturer's instructions. Briefly, after $6 \mathrm{~h}$ treatment with Calyculin or vehicle, cells were incubated with a solution containing $2.0 \mu \mathrm{M}$ Calcein $\mathrm{AM}$ and $4.0 \mu \mathrm{M}$ EthD-III in PBS for $30 \mathrm{~min}$ at $37^{\circ} \mathrm{C}, 5 \% \mathrm{CO}_{2}$, and then visualized under inverted fluorescent microscope (Leica DM IRB). Live cells were distinguished by the presence of ubiquitous intracellular esterase activity, determined by the enzymatic conversion of the nonfluorescent cell-permeant calcein AM to the green fluorescent Calcein. Cell death was detected by the EthD-III dye, which enters dead cells, thereby producing a bright red fluorescence. Percentage of live and dead cells was achieved by counting the ratio of green/red positive cells to the total number of cells (given by the Hoechst staining of nuclei).

\section{Proliferation assay}

To assess the effect of Calyculin on proliferation, HUVECs were seeded onto 96 wells plate at increasing density and allowed to settle overnight $\left(37^{\circ} \mathrm{C}, 5 \% \mathrm{CO}_{2}\right)$. Then, cells were incubated with Calyculin $1 \mathrm{nM}$ or vehicle for $18 \mathrm{~h}$, after which the old media was replaced with fresh warm media $(100 \mathrm{uL} /$ well) and the number of viable cells in proliferation assay was determined using the CellTiter $96^{\circledR}$ Aqueous Non-Radioactive Cell Proliferation (MTS) Kit (Promega). $20 \mu \mathrm{L}$ of the MTS substrate was added to each well and the plate was incubated at $37^{\circ} \mathrm{C}$ for 3 hours, then the absorbance at $490 \mathrm{~nm}$ was recorded using an ELISA plate reader. The correlation coefficient of the curve was used to assess whether the absorbance proportionally correlated with the relative number of cells, as suggested by the Promega manufacturer's instruction. 


\section{Cellular Physiology Cell Physiol Biochem 2015;36:384-394 \begin{tabular}{ll|l} 
and Biochemistry & $\begin{array}{l}\text { DOI: 10.1159/000430257 } \\
\text { Published online: May 07, } 2015\end{array}$ & $\begin{array}{l}\text { O 2015 S. Karger AG, Basel } \\
\text { www.karger.com/cpb }\end{array}$ \\
\cline { 2 - 3 }
\end{tabular} \\ Iacobazzi et al.: PP1 b Role in Angiogenesis}

Migration assay

After reaching the confluence, the cell monolayer was scratched using a P1000 tip at the centre of the well. Then, the medium was exchanged to complete EGM with $2 \mathrm{mM}$ of Hydroxyurea (Sigma) to induce growth arrest. In order to investigate the involvement of PP1 on cell migration, the assay was performed in the presence of the PP1 inhibitor Calyculin (1 nM, SIGMA), Okadaic Acid (1 nM, Enzo Life Scineces), Tautomycin (10 nM, Enzo Life Sciences) or vehicle, which were added $6 \mathrm{~h}$ before the scratch.

The same protocol was performed with transfected HUVEC. 24h after siRNA and/or DNA transfection, confluent HUVEC monolayer was scratched using a P1000 tip at the centre of the well. Images were taken using a bright-field inverted microscope (at 10X). The percentage of gap closure was calculated using the Zeiss Axiovert software (Carl Zeiss Microscopy, Jena, Germany), measuring 5 distances per field of view of the leading edges at the time of the scratch and $24 \mathrm{~h}$ later. Each experiment was performed in triplicate and repeated 3 times.

In vitro matrigel assay

Six hours Calyculin pre-treated HUVEC or 24h siRNA transfected-HUVECs were seeded in 96 well plates, previously filled with $40 \mu \mathrm{L}$ of complete or reduced-growth factors Matrigel (BD Bioscience) and placed at $37^{\circ} \mathrm{C}$ for $20 \mathrm{~min}$ to allow matrix solidification. HUVECs vehicle-treated or pre-treated with scrambled siRNA served as normalization control. For each condition, triplicate wells were set up and experiments were repeated in three independent experiments. The cells were carefully dispensed onto the solidified Matrigel and allowed to settle and form networks for $9 \mathrm{~h}$, after which pictures were taken using a bright-field inverted microscope. The length of network was quantified using the Image-Pro Plus software (Media Cybernetics, UK). All images were taken at 5X magnification.

\section{Staining for Cytoskeletal Proteins}

Control and PP1c $\beta$ siRNA transfected HUVECs were grown until approximately $60 \%$ confluence on glass coverslips. Then, cells were fixed at room temperature for 20 minutes in $4 \%$ paraformaldehyde and permeabilized for 10 minutes with $0.1 \%$ Triton X-100 in PBS, prior to incubation with primary antibodies provided by the Actin Cytoskeleton and Focal Adhesion Staining kit (Millipore). For F-actin staining, cells were incubated with tetrarhodamine isothiocyanate (TRITC)-Phalloidin, while for detection of focal adhesions, cells were immunostained, with anti-vinculin antibody, followed by incubation with FITCconjugated anti mouse secondary antibody. Coverslips were mounted on glass slides with Vectashield Hardset Mounting Medium with DAPI (Vector Laboratories), and images were obtained using a confocal fluorescence microscope (Leica SP5) with a 63x oil immersion objective.

\section{Proteins extraction and Western Blotting}

Right ventricular specimens were homogenised in the presence of RIPA buffer, containing protease inhibitor cocktail and phosphatase inhibitor cocktails 2 and 3 (Sigma). HUVECs were washed with ice-cold PBS after wound healing scratch assay and removed by scraping in the presence of RIPA buffer containing the same protease phosphatase inhibitors. Protein concentration was determined using the Bio-Rad protein assay reagent (Bio-Rad, UK). Detection of proteins by western blot analysis was done following separation of equal amount of cell extracts on 12\% SDS-polyacrylamide gels. Proteins were transferred to nitrocellulose membrane and probed with the anti PP1c $\beta$ (1:200000, Abcam), anti ph-FAK (1:1000, Cell Signaling) and anti FAK (1:1000, Cell Signaling) antibodies. GADPH (1:1000, Cell Signaling) or Laminin (1:1000 Cell Signaling) were used as loading control. For detection, secondary antibody goat anti rabbit (1:5000, Santa Cruz) was used and proteins were detected using an ECL ${ }^{\mathrm{TM}}$ detection system (Amersham, GE Healthcare).

\section{Statistical analysis}

Data are expressed as mean \pm SEM. Statistical analysis was performed using SigmaPlot 12.2. All data was tested for normality using Shapiro-Wilk test. Samples were analyzed by Student's t test. Results were considered significant if $\mathrm{p} \leq 0.05$. 
Fig. 1. $P P 1 c \beta$ protein is upregulated in cyanotic compared with acyanotic heart. A, Representative Western blot and densitometric analysis of PP1c $\beta$ protein expression level in myocardium of acyanotic (AC) and cyanotic (CC) patients. PP1c $\beta$ bands were normalized to GAPDH levels. Data are presented as means \pm standard errors of the mean. ${ }^{*}<0.05(\mathrm{n}=6)$. B, PP$1 c \beta$ protein immunostaining of paraffin-embedded heart tissue from acyanotic (left panel) and cyanotic (right panel) patients using PP1c $\beta$-specific antibody. Diaminobenzidine (DAB)

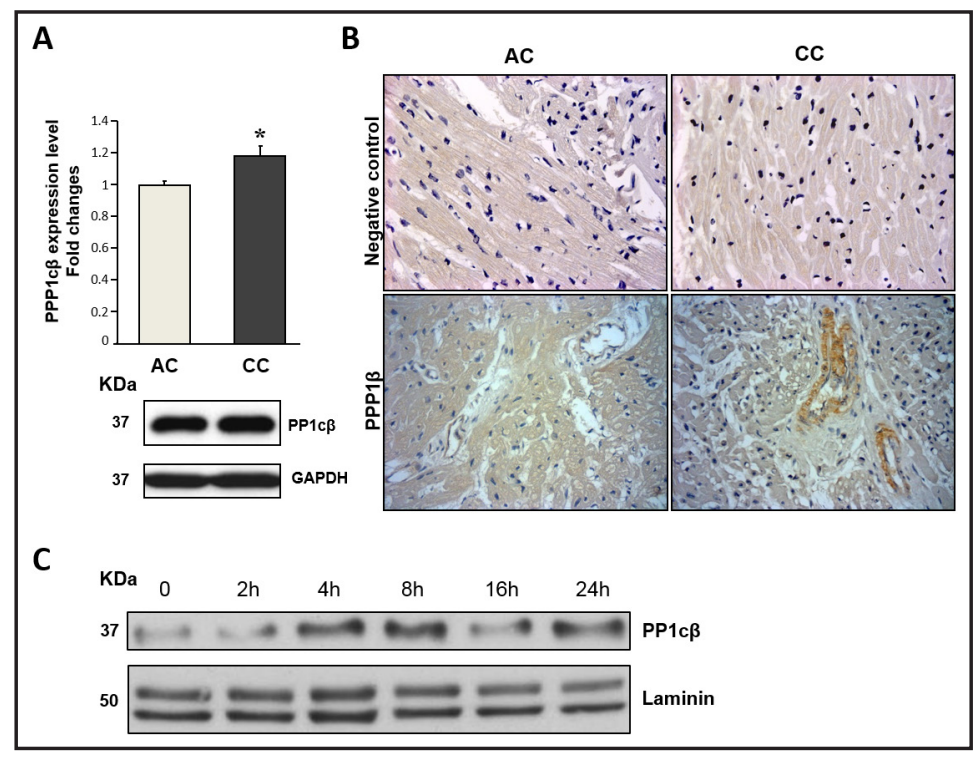
staining (brown) reveals expression of PP1c $\beta$ in cyanotic tissues. $C$, Representative Western blot showing the time-dependently increase of PP1c $\beta$ protein expression in $\mathrm{CoCl}_{2}$-stimulated HUVECs $(n=3)$.

\section{Results}

$P P 1 c \beta$ protein is upregulated in cyanotic compared with acyanotic heart

In a previous study [19], hundreds of genes were identified as differentially expressed in cyanotic versus acyanotic heart. In particular, a number of upregulated genes were involved in apoptosis, cell movement, morphogenesis, and development, indicating genetic remodeling of the cyanotic myocardium in response to chronic hypoxia. Among these, PP1c $\beta$ isoform was significantly upregulated in the cyanotic heart (3.8x fold change). Hence, we evaluated the protein levels of this gene in the myocardium of cyanotic and acyanotic children by Western blotting. As shown in Fig. 1 a, a significant increase of the protein level in the cyanotic, and therefore hypoxic tissue, was observed. By immunohistochemistry we confirmed the overexpression of PP1c $\beta$ protein in the cyanotic specimens (Fig. $1 \mathrm{~b}$ ). Interestingly, the positive staining was located mainly in the endothelial wall of small vessels that perfuse the myocardium. This might explain why PP1c $\beta$ protein expression difference between cyanotic and acyanotic hearts wasn't so great in the Western blotting experiment, as it reflected only the expression changes in endothelial cells.

In order to reproduce the hypoxic environment in vitro, HUVECs were incubated for different times with the hypoxia-mimicking agent $\mathrm{CoCl}_{2}$. Cobalt has been widely used as a hypoxia mimic in cell culture and it is known to activate hypoxic signalling by stabilizing the hypoxia inducible transcription factor $1 \alpha(\mathrm{HIF} 1 \alpha)$ [24, 25]. As shown in Fig. $1 \mathrm{c}, \mathrm{CoCl}_{2}$ timedependently induced the expression of PP1c $\beta$, with the highest expression observed at $8 \mathrm{~h}$.

Inhibition of PP1c $\beta$ activity by pharmacological and siRNA approach reduces HUVEC migratory capacity

To assess the role of PP1c $\beta$ in cell migration, we performed a scratch assay in presence of different protein phosphatase 1 and 2 (PP1 and PP2) pharmacological inhibitors. The pretreatment of HUVEC with Okadaic Acid reduced the percentage of gap closure after the wounding, although not significantly, likely because of its higher selectivity for the isoform 2 of the protein phosphatase [26]. However, with the more specific PP1 inhibitors Calyculin and Tautomycin, cell migration was significantly delayed, in comparison with untreated cells (Fig. 2 a-b), with Calyculin being more effective than Tautomycin. In order to ensure that the treatment did not impair the vital functions of the cells, viability and proliferation assays were performed in presence and absence of Calyculin. Exposure to calyculin did not 


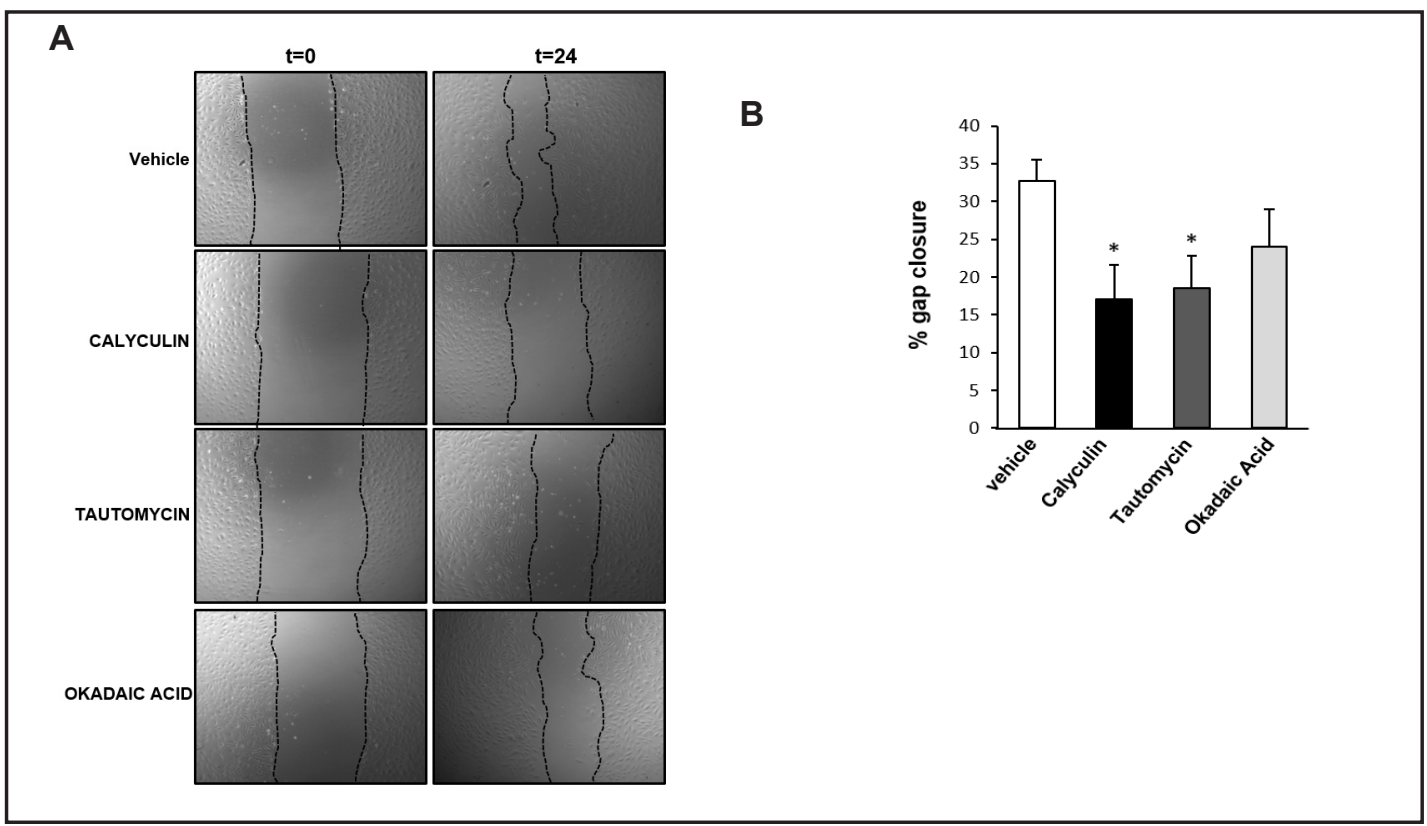

Fig. 2. $P P 1 c \beta$ pharmacological inhibition effect on HUVEC migration. A, Confluent HUVEC monolayers were incubated for $6 \mathrm{~h}$ with Calyculin $(1 \mathrm{nM})$, Tautomycin $(10 \mathrm{nM})$ or Okadaic Acid (1 nM) and then scratched in the presence of Hydroxyurea (2 $\mathrm{mM}$ ) to induce growth arrest. Phase contrast images were collected after 24h. All the inhibitors delayed HUVEC migration, with Calyculin and Tautomycin exerting a significant effect. B, Representative histograms indicating the percentage of gap closure: Values are means \pm SEM of 3 independent experiments, ${ }^{*} \mathrm{P}<0.05$.

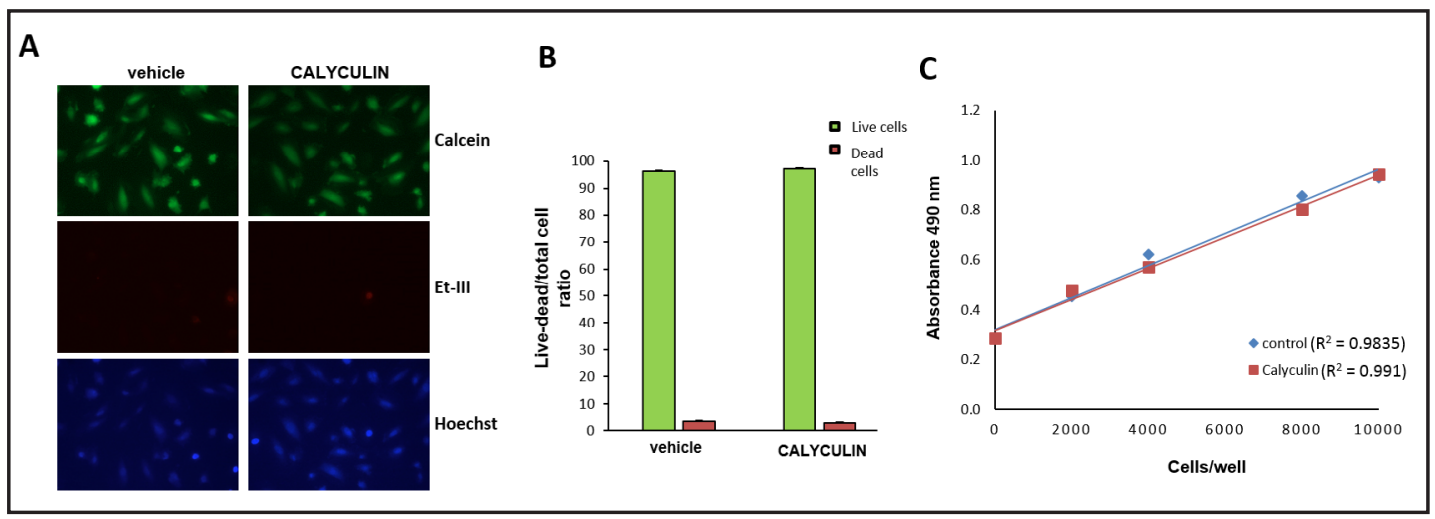

Fig. 3. Calyculin treatment does not affect cell viability and proliferation. A, Simultaneous fluorescent imaging on live cells showed that the same ratio of viable (green) and dead (red) cells were detected in the untreated and calyculin-treated groups. B, Proliferation curve of control and calyculin-treated cells. The correlation coefficient of the line was $>0.98$ in both groups, indicating a linear response between cell number and absorbance.

affect cell viability, as the capacity of cells to enzymatically convert the nonfluorescent cellpermeable calcein AM to the green fluorescent calcein was unaltered in either the control or calyculin treated cells. The same ratio of dead cells was equally detected in both groups (Fig. $3 \mathrm{a}-\mathrm{b}$ ). Likewise proliferation capacity was not affected by the pharmacological treatment, compared to the untreated cells (Fig. $3 \mathrm{c}$ ).

Since all of the available inhibitors non-specifically inhibit-PP1 and PP2 activity [26], we used the siRNA approach to selectively knock down the expression of PP1c $\beta$. Successful downregulation of PP1c $\beta$ protein level was determined following the scratch assay by using 
A

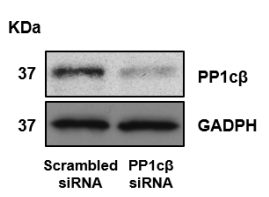

C
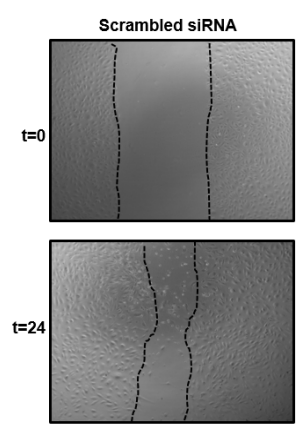

B
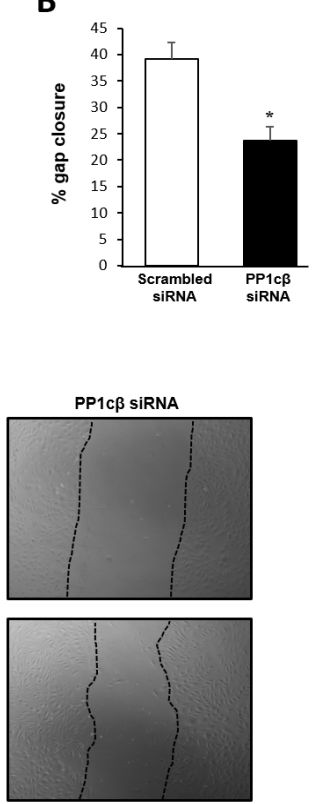

D

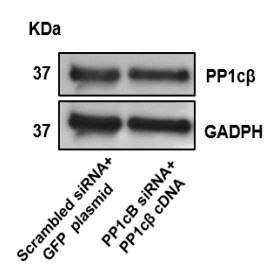

E

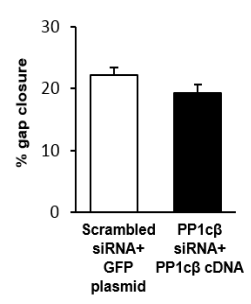

$\mathbf{F}$

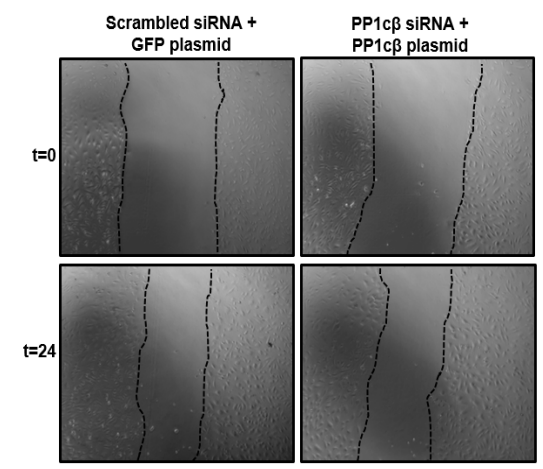

Fig. 4. PP1c $\beta$ gene silencing reduces HUVEC migratory capability. A, Representative Western blot showing PP1c $\beta$ protein downregulation $24 \mathrm{~h}$ after transfection compared to the control (scrambled siRNA). B, Representative histograms indicating the percentage of gap closure $24 \mathrm{~h}$ following the scratch in PP1c $\beta$-silenced and control (scrambled siRNA) HUVEC. Data are means \pm SEM of $n=5$, ${ }^{*} p<0.05$ versus control. C, Confluent HUVEC monolayers, pre-transfected with PP1c $\beta$ siRNA and scrambled control siRNA, were scratched and wound area images were acquired at $0 \mathrm{~h}$ and $24 \mathrm{~h}$ following the scratch. D, Western blot showing that PP$1 \mathrm{c} \beta$ level in siRNA transfected HUVEC is restored after transfection with PP1c $\beta$ plasmid. E, Representative histograms indicating the percentage of gap closure $24 \mathrm{~h}$ following the scratch in the experimental group (PP1c $\beta$ siRNA $+P P 1 c \beta$ plasmid) and control (scrambled siRNA/GFP plasmid). Data are means \pm SEM of $n=3$. $F$, Confluent HUVEC monolayers, pre-transfected with PP1c $\beta$ siRNA/PP1c $\beta$ plasmid and scrambled siRNA/ GFP plasmid (control), were scratched and wound area images were acquired at $0 \mathrm{~h}$ and $24 \mathrm{~h}$ following the scratch.

Western blotting analysis (Fig. 4 a).

Wound healing scratch assay was repeated $24 \mathrm{~h}$ post transfection with PP1c $\beta$ siRNA or scrambled siRNA (control). The average wound closure at $24 \mathrm{~h}$ following the scratch was still reduced in PP1c $\beta$ siRNA transfected group compared to the control (Fig. 4 b-c), even though the reduction was not as effective as the calyculin treatment, maybe due to the low transfection efficiency (30\%). However, when PP1c $\beta$ expression was re-established by the subsequent transfection with PP1c $\beta$ cDNA encoding plasmid, the cell migration of the cotransfected HUVEC was restored nearly to the migration level observed in the control group (Fig. 4 d-f).

\section{$P P 1 c \beta$ is not involved in the endothelial tube formation process of angiogenesis}

Since angiogenesis is a complex process with multiple steps and PP1c $\beta$ is involved in the early phase of cell migration, we set out to investigate whether this protein phosphatase has also a role in the later process of tube formation. To this end, calyculin and vehicle pretreated HUVECs were seeded onto complete (data not shown) or reduced-growth factors Matrigel matrix to allowed forming capillary-like structures. No difference between the experimental and control groups were found by quantifying the total tube length (Fig. 5 $a-b)$. Similarly, transfection with PP1c $\beta$ siRNA showed no effect on HUVEC tube formation capability (Fig. 5 c-d). 
Fig. 5. $P P 1 c \beta$ is not involved in the endothelial tube formation process of angiogenesis. A, HUVECs pre-incubated with Calyculin $(1 \mathrm{nM}, 6 \mathrm{~h})$ or vehicle (control) were plated onto Matrigel matrices, and endothelial tube formation assessed after $24 \mathrm{~h}$ of incubation. Representative images of capillary-like structures from each group are shown. B, Graph shows average total tube length per well, data presented as mean \pm SEM (Student's t test, $p>0.05$ vs. control, $n=5$ ). C, HUVECs, pre-transfected with PP$1 \mathrm{c} \beta$ siRNA and scrambled siRNA (control), were plated onto Matrigel matrices, and endothelial

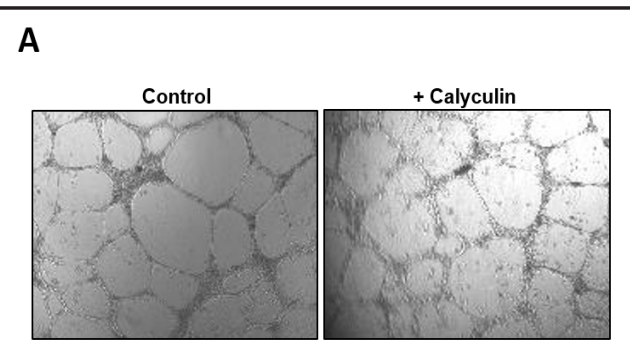

C

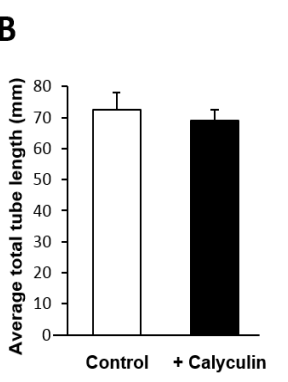

D

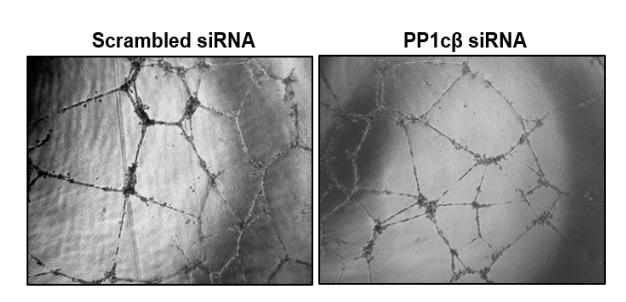

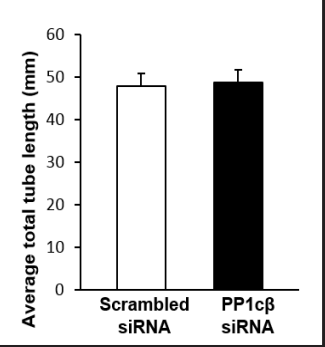

tube formation assessed after $24 \mathrm{~h}$ of incubation. Representative images of capillary-like structures from each group are shown. D, Graph shows average total tube length per well, data presented as mean \pm SEM (Student's t test, $\mathrm{p}>0.05$ vs. control, $\mathrm{n}=5$ ).

Fig. 6. PP1c $\beta$ knockdown induces cytoskeletal reorganization in endothelial cells. A, Immunofluorescent staining of scrambled siRNA and PP1c $\beta$ SiRNA HUVEC was performed, $24 \mathrm{~h}$ after transfection, with TRITC-Phalloidin (red) and anti-vinculin antibody (green). Yellow arrows in scrambled siRNA cells point to focal adhesions anchoring to stress fibers. Compared with the control cells, PP1c $\beta$-knockdown cells showed a dramatic loss of actin stress fibers and focal adhesion sites (vinculin staining). B, Immunoblot analysis of FAK and phosphorylated FAK in control and knockdown groups. In PP1c $\beta$ knockdown cells lysate, a reduction in Tyr-397 (FAK) was found, compared to the control cells lysate. Intensity levels of ph-FAK

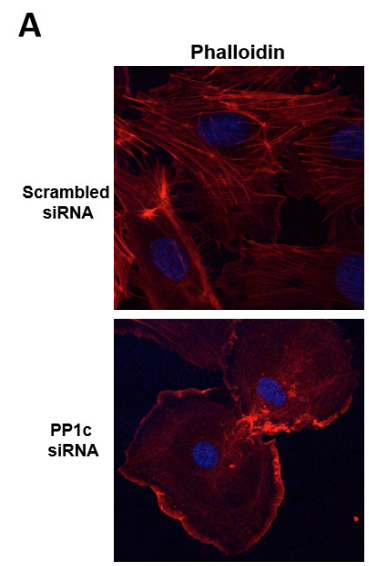

B

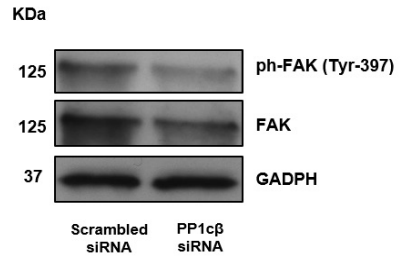

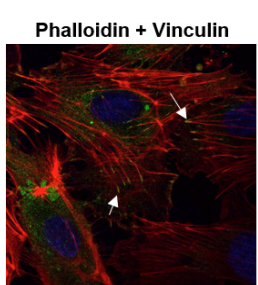

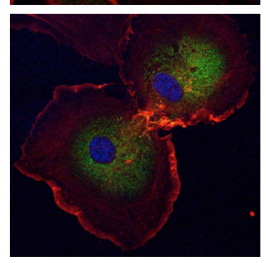

C

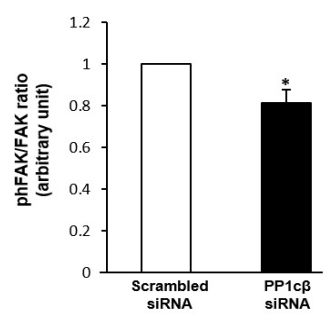

(Tyr-397) and total FAK were normalized to GADPH and ratio of normalized ph-FAK and FAK were plotted in arbitrary units.

PP1c $\beta$ knockdown induces morphological and cytoskeletal changes in endothelial cells

Since cell migration involves cytoskeleton reorganization through focal adhesions and focal adhesion kinase (FAK) signaling pathway, we examined the effect of PP1c $\beta$ knockdown on cell morphology and actin cytoskeleton arrangement, whose organization is essential to 


\section{Cellular Physiology Cell Physiol Biochem 2015;36:384-394

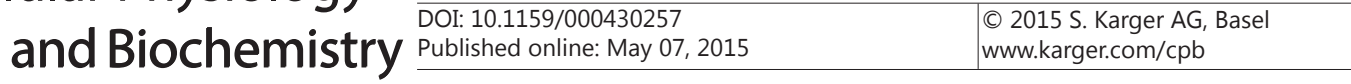 \\ Iacobazzi et al.: PP1 b Role in Angiogenesis}

give structural support to the cells and mediate intra- and extra-cellular movement. Confocal imaging revealed that, compared with controls, $\mathrm{PP} 1 \mathrm{c} \beta$ depletion resulted in a complete loss of the regular stress fibers organization, as detected by Phalloidin staining for the F-actin filaments. In addition, focal adhesions, that serve as nucleation sites for actin filaments and therefore support the cell structure, were examined in control and knockdown cells. The large pointed focal adhesions anchoring stress fibers, observed in the control group (detected by staining for vinculin), were completely lost in the PP1c $\beta$ silenced cells (Fig. 6 a). Furthermore, PP1c $\beta$ knockdown triggered a significant reduction in Tyr-397 phosphorylation of focal adhesion kinase (FAK), which is essential for FAK activation. These findings suggest a role for PP1c $\beta$ in the signalling pathway that drives cell adhesion and migration (Fig. 6 b-c).

\section{Discussion}

Angiogenesis refers to the formation of new capillaries from already existing vessels through a complex process that involves multiple steps, including degradation of ECM surrounding the parent vessel, migration and proliferation of endothelial cells, assembly of the new blood vessel, lumen formation and construction of the mural layer of the vessel wall [27]. This mechanism is essential during embryonic development and wound healing. However, if dysfunctional, it may have important pathogenic consequences, as reported in vascular diseases and cancer growth.

The current study aimed to determine the contribution of the PP1c $\beta$ isoform in the regulation of angiogenesis, through investigation of endothelial cell migration and tube formation in vitro.

Previous studies have reported PP1c $\beta$ localization to focal adhesions and association of PP1c $\beta$ with focal adhesion [28]. However no direct role for PP1c $\beta$ in cell migration has been shown. Focal adhesions are membrane-associated macromolecules involved in the linkage of integrin adhesion molecules to the actin cytoskeleton and are associated with protein complexes including vinculin, paxillin and focal adhesion kinases (FAK) [29, 30], all of which play a crucial role in cell adhesion and motility. In particular, FAK signalling pathway is essential for cell migration and its activation is orchestrated by a complex mechanism resulting from the interaction of several kinases and phosphatases [28, 31]. A previous study showed that PP1 is involved in FAK activation through its dephosphorylation of Ser-722 residue. This event led to the activation of FAK catalytic activity by increasing the phosphorylation of the Tyr-397 autokinase, ultimately resulting in FAK activation [28]. Our finding that PP1 knockdown reduced the phosphorylation status of FAK supports the above studies. FAKmediated turnover of focal adhesions, together with p38-mediated actin polymerization, allow cell contraction through formation of stress fibres, consequently enabling endothelial cell migration [32]. Thus, FAK is a positive regulator of cell motility [33]. Whether PP1c $\beta$ is also involved in the endothelial tube formation phase of the angiogenic process was also assessed. Our results showed no effects of knocking-down PP1c $\beta$ on HUVEC tube formation. The presence of growth factors in either complete or reduced-growth factors Matrigel may explain the absence of effect in network formation. Different growth factors are involved in the tube formation of vascular endothelial cells, such as transforming growth factor- $\alpha$ (TGF- $\alpha$ ) and $-\beta$ (TGF- $\beta$ ), epidermal growth factor (EGF), and basic fibroblast growth factor (bFGF) [34]. Besides such a variety of growth factors, laminin, which is one of the major vascular basement membrane components, is also shown to be a crucial factor in endothelial tube formation in cultured HUVECs [35]. Laminin is also the main component of Matrigel followed by collagen IV, heparin sulfate proteoglycans, entactin and nidogen [36]. These ECM proteins control vascular morphogenesis through specific integrin-dependent signaling pathways [37] that may counterbalance the effect of PP1c $\beta$ silencing, where PP1c $\beta$ may be part of an unrelated signaling pathway. 


\begin{tabular}{|c|c|c|}
\hline Cellular Physiology & Cell Physiol Biochem 2015;36:384-394 & \\
\hline and Biochemistry & $\begin{array}{l}\text { DOI: } 10.1159 / 000430257 \\
\text { Published online: May 07, } 2015\end{array}$ & $\begin{array}{l}\text { O } 2015 \text { S. Karger AG, Basel } \\
\text { www.karger.com/cpb }\end{array}$ \\
\hline
\end{tabular}

\section{Conclusions}

Our findings show for the first time that PP1c $\beta$, the catalytic isoform of PP1 plays a role in endothelial cell migration, whereby PP1c $\beta$ knockdown and pharmacological inhibition reduce the migration of HUVEC cells in culture. The mechanism, by which PP1c $\beta$ regulates endothelial cell migration, involves the interplay of actin cytoskeleton proteins and focal adhesion molecules signaling. Our study helps elucidating endothelial cell migration mechanism, specifically in the context of cancer-induced angiogenesis, and highlights PP1c $\beta$ as a possible promising target for antiangiogenic therapy and inhibition of tumor growth.

\section{Acknowledgements}

We are grateful to Professors M-S Suleiman and AP Halestrap for valuable comments. This study was supported by the British Heart Foundation, The Garfield Weston Trust and NIHR Bristol Biomedical Research Unit in Cardiovascular Medicine. An Intermediate Research Fellowship from the British Heart Foundation supported MT Ghorbel. The experiments in this study comply with current laws in the UK.

\section{Disclosure Statement}

The authors declare that they have no conflict of interest.

\section{References}

1 Dvorak HF: Angiogenesis: Update 2005. J Thromb Haemost 2005;3:1835-1842.

2 Hoeben A, Landuyt B, Highley MS, Wildiers H, Van Oosterom AT, De Bruijn EA: Vascular endothelial growth factor and angiogenesis. Pharmacol Rev 2004;56:549-580.

3 Ceulemans H, Bollen M: Functional diversity of protein phosphatase-1, a cellular economizer and reset button. Physiol Rev 2004;84:1-39.

4 Jarray R, Allain B, Borriello L, Biard D, Loukaci A, Larghero J, Hadj-Slimane R, Garbay C, Lepelletier Y, Raynaud F: Depletion of the novel protein phactr-1 from human endothelial cells abolishes tube formation and induces cell death receptor apoptosis. Biochimie 2011;93:1668-1675.

5 Cohen PT: Protein phosphatase 1--targeted in many directions. J Cell Sci 2002;115:241-256.

6 Shi Y: Serine/threonine phosphatases: Mechanism through structure. Cell 2009;139:468-484.

7 Egloff MP, Johnson DF, Moorhead G, Cohen PT, Cohen P, Barford D: Structural basis for the recognition of regulatory subunits by the catalytic subunit of protein phosphatase 1. EMBO J 1997;16:1876-1887.

8 Saadat M, Kakinoki Y, Mizuno Y, Kikuchi K, Yoshida MC: Chromosomal localization of human, rat, and mouse protein phosphatase type 1 beta catalytic subunit genes (ppp1cb) by fluorescence in situ hybridization. Jpn J Genet 1994;69:697-700.

9 Csortos C, Czikora I, Bogatcheva NV, Adyshev DM, Poirier C, Olah G, Verin AD: Timap is a positive regulator of pulmonary endothelial barrier function. Am J Physiol Lung Cell Mol Physiol 2008;295:L440-450.

10 Walsh JE, Young MR: Interrelationship between protein phosphatase 1 and tgf- $\{$ beta\} in regulating motility and cytoskeletal architecture of endothelial cells. Anticancer Res 2010;30:4861-4866.

11 Allain B, Jarray R, Borriello L, Leforban B, Dufour S, Liu WQ Pamonsinlapatham P, Bianco S, Larghero J, Hadj-Slimane R, Garbay C, Raynaud F, Lepelletier Y: Neuropilin-1 regulates a new vegf-induced gene, phactr-1, which controls tubulogenesis and modulates lamellipodial dynamics in human endothelial cells. Cell Signal 2012;24:214-223.

12 Lin CY, Tan BC, Liu H, Shih CJ, Chien KY, Lin CL, Yung BY: Dephosphorylation of nucleophosmin by pp1beta facilitates prb binding and consequent e2f1-dependent DNA repair. Mol Biol Cell 2010;21:4409-4417.

13 Keller G, Schally AV, Nagy A, Baker B, Halmos G, Engel JB: Effective therapy of experimental human malignant melanomas with a targeted cytotoxic somatostatin analogue without induction of multi-drug resistance proteins. Int J Oncol 2006;28:1507-1513.

14 Couvelard A, Hu J, Steers G, O'Toole D, Sauvanet A, Belghiti J, Bedossa P, Gatter K, Ruszniewski P, Pezzella F: Identification of potential therapeutic targets by gene-expression profiling in pancreatic endocrine tumors. Gastroenterology 2006;131:1597-1610. 


\section{Cellular Physiology Cell Physiol Biochem 2015;36:384-394 \begin{tabular}{l|l|l} 
DOI: 10.1159/000430257 & (C) 2015 S. Karger AG, Basel
\end{tabular} \\ Iacobazzi et al.: PP1 b Role in Angiogenesis}

15 Chen R, Yi EC, Donohoe S, Pan S, Eng J, Cooke K, Crispin DA, Lane Z, Goodlett DR, Bronner MP, Aebersold R, Brentnall TA: Pancreatic cancer proteome: The proteins that underlie invasion, metastasis, and immunologic escape. Gastroenterology 2005;129:1187-1197.

16 Winter SL, Bosnoyan-Collins L, Pinnaduwage D, Andrulis IL: The interaction of pp 1 with brca1 and analysis of their expression in breast tumors. BMC Cancer 2007;7:85.

17 Sun D, Zhou M, Kowolik CM, Trisal V, Huang Q, Kernstine KH, Lian F, Shen B: Differential expression patterns of capping protein, protein phosphatase 1 , and casein kinase 1 may serve as diagnostic markers for malignant melanoma. Melanoma Res 2011;21:335-343.

18 Pugh CW, Ratcliffe PJ: Regulation of angiogenesis by hypoxia: Role of the hif system. Nat Med 2003;9:677684.

19 Ghorbel MT, Cherif M, Jenkins E, Mokhtari A, Kenny D, Angelini GD, Caputo M: Transcriptomic analysis of patients with tetralogy of fallot reveals the effect of chronic hypoxia on myocardial gene expression. J Thorac Cardiovasc Surg 2010;140:337-345 e326.

20 Lemus-Varela ML, Flores-Soto ME, Cervantes-Munguia R, Torres-Mendoza BM, Gudino-Cabrera G, Chaparro-Huerta V, Ortuno-Sahagun D, Beas-Zarate C: Expression of hif-1 alpha, vegf and epo in peripheral blood from patients with two cardiac abnormalities associated with hypoxia. Clin Biochem 2010;43:234239.

21 Starnes SL, Duncan BW, Kneebone JM, Rosenthal GL, Jones TK, Grifka RG, Cecchin F, Owens DJ, Fearneyhough C, Lupinetti FM: Vascular endothelial growth factor and basic fibroblast growth factor in children with cyanotic congenital heart disease. J Thorac Cardiovasc Surg 2000;119:534-539.

22 Harris AL: Hypoxia--a key regulatory factor in tumour growth. Nat Rev Cancer 2002;2:38-47.

23 Hatipoglu OF, Hirohata S, Cilek MZ, Ogawa H, Miyoshi T, Obika M, Demircan K, Shinohata R, Kusachi S, Ninomiya Y: Adamts1 is a unique hypoxic early response gene expressed by endothelial cells. J Biol Chem 2009;284:16325-16333.

24 Wang GL, Semenza GL: Desferrioxamine induces erythropoietin gene expression and hypoxia-inducible factor 1 DNA-binding activity: Implications for models of hypoxia signal transduction. Blood 1993;82:36103615 .

25 Vengellur A, LaPres JJ: The role of hypoxia inducible factor 1alpha in cobalt chloride induced cell death in mouse embryonic fibroblasts. Toxicol Sci 2004;82:638-646.

26 Favre B, Turowski P, Hemmings BA: Differential inhibition and posttranslational modification of protein phosphatase 1 and 2a in mcf7 cells treated with calyculin-a, okadaic acid, and tautomycin. J Biol Chem 1997;272:13856-13863.

27 Goodwin AM: In vitro assays of angiogenesis for assessment of angiogenic and anti-angiogenic agents. Microvasc Res 2007;74:172-183.

28 Bianchi M, De Lucchini S, Marin O, Turner DL, Hanks SK, Villa-Moruzzi E: Regulation of fak ser-722 phosphorylation and kinase activity by gsk3 and pp1 during cell spreading and migration. Biochem J 2005;391:359-370.

29 Burridge K, Nuckolls G, Otey C, Pavalko F, Simon K, Turner C: Actin-membrane interaction in focal adhesions. Cell Differ Dev 1990;32:337-342.

30 Turner CE, Burridge K: Transmembrane molecular assemblies in cell-extracellular matrix interactions. Curr Opin Cell Biol 1991;3:849-853.

31 Zhao X, Guan JL: Focal adhesion kinase and its signaling pathways in cell migration and angiogenesis. Adv Drug Deliv Rev 2011;63:610-615.

32 Lamalice L, Le Boeuf F, Huot J: Endothelial cell migration during angiogenesis. Circ Res 2007;100:782-794.

33 Hanks SK, Ryzhova L, Shin NY, Brabek J: Focal adhesion kinase signaling activities and their implications in the control of cell survival and motility. Front Biosci 2003;8:d982-996.

34 Okamura K, Morimoto A, Hamanaka R, Ono M, Kohno K, Uchida Y, Kuwano M: A model system for tumor angiogenesis: Involvement of transforming growth factor-alpha in tube formation of human microvascular endothelial cells induced by esophageal cancer cells. Biochem Biophys Res Commun 1992;186:1471-1479.

35 Kubota Y, Kleinman HK, Martin GR, Lawley TJ: Role of laminin and basement membrane in the morphological differentiation of human endothelial cells into capillary-like structures. J Cell Biol 1988;107:1589-1598.

36 Kleinman HK, McGarvey ML, Hassell JR, Star VL, Cannon FB, Laurie GW, Martin GR: Basement membrane complexes with biological activity. Biochemistry 1986;25:312-318.

37 Davis GE, Senger DR: Endothelial extracellular matrix: Biosynthesis, remodeling, and functions during vascular morphogenesis and neovessel stabilization. Circ Res 2005;97:1093-1107. 